\title{
A IMPORTÂNCIA DA ANÁLISE ECONÔMICA DO DIREITO E CONEXÕES COM O DIREITO CIVIL
}

\author{
Danilo Cordeiro Maia* \\ Wallace Fabrício Paiva Souza*
}

RESUMO: O Direito e a Economia possuem uma forte conexão, e uma forma de pensá-los juntos é por meio da Análise Econômica do Direito, escola que trabalha postulados econômicos no Direito em prol de uma maior eficiência. Propôs-se este trabalho, assim, para demonstrar algumas conexões entre o Direito Civil e a referida escola, o que é de extrema importância, fazendo um recorte metodológico quanto aos institutos da propriedade, responsabilidade civil e contratos. Para a condução deste trabalho, foi utilizado o método exploratório, sendo o seu objeto estudado por meio de trabalhos especializados que retratam o tema em questão.

Palavras-chave: Direito Civil Contemporâneo; Análise Econômica do Direito; Propriedade; Responsabilidade Civil; Contratos.

\section{THE IMPORTANCE OF ECONOMIC ANALYSIS OF LAW AND CONNECTIONS WITH CIVIL LAW}

\begin{abstract}
Law and Economics have a strong connection, and a way of thinking them together is through the Economic Analysis of Law, a school that works economically in legal postulates for greater efficiency. This work was therefore proposed to demonstrate some connections between Civil Law and this school, which is extremely important, making a methodological cut as regards the institutes of property, civil liability and contracts. In order to conduct this work, the exploratory method was used, and its object was studied through specialized works that portray the subject in question.
\end{abstract}

Keywords: Contemporary Civil Law; Economic Analysis of Law; Property; Civil Responsability; Contracts.

*Advogado, Coordenador Jurídico no escritório Antunes Mascarenhas Advogados (setor de recuperação de crédito), Especialista em Direito de Empresa pela PUC Minas, Pós-graduando em Compliance e Integridade Corporativa pela PUC Minas, Graduado em Direito pelo Centro Universitário UNA. E-mail: danilocordeiromaia@gmail.com.

*Professor Universitário, Advogado, Doutorando em Direito Privado pela PUCMinas, Mestre em Direito Empresarial pela Faculdade de Direito Milton Campos (Bolsista CAPES), Especialista em Direito e Processo Civil pela FEAD. E-mail: wallacefabricio1@hotmail.com. 


\section{INTRODUÇÃO}

O Direito, como já verificado ao longo da história, não é algo absoluto, inerente à natureza humana, sofrendo alterações de acordo com as influências políticas, econômicas e sociais. E o Direito, ao mesmo tempo em que é influenciado, também tem um papel fundamental na Política, Economia e no Social, por exemplo. Para este trabalho, então, escolheu-se trabalhar a Análise Econômica do Direito, escola que tem como finalidade a implementação dos postulados econômicos na aplicação e interpretação do Direito, para que se tenha uma maior eficiência nas relações.

A relação entre Direito e Economia é enorme, de modo que devem andar juntos, podendo estabelecer a relação com vários ramos do Direito, como Empresarial, Civil, Penal, Processual, Econômico, Administrativo, dentre outros. É natural que alguns ramos do Direito tenham uma facilidade maior em considerar postulados econômicos na sua aplicação como se dá com o Direito Empresarial, que está mais diretamente relacionado ao mercado. Porém, em alguns ramos, há uma certa resistência quanto à Análise Econômica do Direito por parte de alguns doutrinadores, como no Direito Civil, embora de natureza eminentemente privada. Porém, como será demonstrado, há fortes conexões entre o Direito Civil e a Análise Econômica do Direito.

A presente pesquisa se justifica, então, pela importância que pode ter no Direito Civil a utilização do método da Análise Econômica do Direito. Um estudo do Direito Civil com base em postulados econômicos pode ter um papel fundamental numa maior eficiência nas relações. Obviamente, que não se pretende um estudo do Direito com base puramente em postulados econômicos, o que nem seria permitido pelo ordenamento jurídico brasileiro, mas sim demonstrar outra visão. A Análise Econômica do Direito é para complementar e não substituir.

Para a condução deste trabalho, então, foi utilizado o método da análise de evolução do entendimento, com a coleta e estudo de doutrina especializada que retrata o tema em questão. Destaca-se, principalmente, a obra do Professor Eduardo Goulart Pimenta, referência obrigatória quando se trata de Análise Econômica do Direito.

A pesquisa foi dividida em três partes. Iniciou-se pelo estudo da escola da Análise Econômica do Direito, com seus principais pressupostos e sua importância. Após, explicou-se

Revista Brasileira de Direito Civil em Perspectiva | e-ISSN: 2526-0243 | Salvador | v. 4 | n. 1 | p. 61 - 79 | Jan/Jun. 2018 
por que juristas e economistas devem conversar mais, ou seja, como a Economia pode ser importante para o Direito e vice-versa. Por fim, diante da impossibilidade de estudar a Análise Econômica do Direito em todos os ramos do Direito, fez-se um recorte metodológico verificando a aplicação da metodologia da ciência econômica junto ao Direito Civil, notadamente quanto aos institutos da propriedade, responsabilidade civil e contratos.

\section{A ESCOLA DA ANÁLISE ECONÔMICA DO DIREITO}

A análise econômica do direito é uma escola que tem como objetivos a implementação dos postulados econômicos na aplicação e interpretação das normas jurídicas, para que se tenha uma maior eficiência nas relações (MONTEIRO, 2013), então para seu estudo é importante fazer breves observações sobre a Economia em si.

Como bem explicado por Eduardo Goulart Pimenta (2006, p. 160), a Economia pode ser considerada como “o ramo das ciências sociais aplicadas destinado à análise da forma pela qual a população gera, organiza e usufrui de seus limitados recursos materiais com o objetivo de atender às suas necessidades e vontades”.

A Economia se torna importante, então, porque os recursos da sociedade são escassos, ou seja, não podem ser produzidos todos os bens e serviços que se desejam, fazendo-se necessário um gerenciamento. Faz-se, assim, um “estudo de como a sociedade escolhe entre suas necessidades e desejos de forma a adequá-los aos recursos materiais de que dispõe e de como a sociedade procura aperfeiçoar a utilização desses mesmos recursos materiais” (PIMENTA, 2006, p. 160).

Para a ciência econômica, o principal ponto a ser observado deve ser a eficiência, de modo que em um raciocínio puramente econômico se analisa a conduta de alguém de acordo com a sua contribuição para “a maximização dos recursos materiais disponíveis ou para sua ótima utilização ou distribuição” (PIMENTA, 2006, p. 160).

Dentre as características marcantes para outros ramos do conhecimento social, destaca-se que a Economia permite:

- quantificar resultados;

- construir identidades quantificáveis;

Revista Brasileira de Direito Civil em Perspectiva | e-ISSN: 2526-0243 | Salvador | v. 4 | n. 1 | p. 61 - 79 | Jan/Jun. 2018 
- estabelecer relações quantitativas entre diferentes categorias de transações;

- desenvolver modelos explicativos da realidade, baseados em sistemas de equações simultâneas;

- proceder a análises fundamentadas em parâmetros quantificados;

- desenvolver sistemas quantitativos para diagnósticos e prognósticos. (ROSSETTI, 2003, p. 35)

Uma análise econômica, então, pressupõe “a apreensão das opções entre diferentes condutas, bem como dos custos, riscos e benefícios envolvidos em cada uma dessas escolhas” (PIMENTA, 2006, p. 162). E quando se fala em estudar o Direito sob uma perspectiva econômica é verificar os custos, benefícios e opções que uma legislação acarreta para os agentes. Como afirma Eduardo Goulart Pimenta (2006, p. 162),

É perfeitamente possível que analisemos as ações dos agentes econômicos e sobre elas construamos modelos em que tais condutas sejam explicadas em função de alterações na legislação que as discipline. Uma das razões do sucesso da análise econômica do Direito como método de estudo da legislação está na constatação de que, em um determinado modelo econômico, a legislação é uma importantíssima variável a ser considerada. Sua capacidade de influência sobre a ocorrência econômica estudada é potencialmente muito elevada e, por isso mesmo, não pode ser deixada de lado.

Iniciada com Ronald H. Coase em 1960, sendo o maior expoente da escola Richard Posner, a Análise Econômica do Direito tinha como maior fundamento trazer segurança e previsibilidade ao ordenamento jurídico, tentando agregar maximização, equilíbrio e eficiência às relações jurídicas (MONTEIRO, 2013).

Como postulados, Paula A. Forgioni (2005, p. 244/247) destaca os seguintes:

a) como há escassez de recursos devido às necessidades humanas, uma alocação mais eficiente gera o incremento do bem-estar e do fluxo das relações econômicas;

b) uma alocação eficiente ocorre quando uma sociedade não pode ainda fazer modificações capazes de melhorar a posição de alguém sem prejudicar a de outrem, o que é denominado como Ótimo Paretiano. Contudo, esse postulado é criticado por ser quase impossível proceder a uma mudança de política pública sem prejudicar alguém;

c) o livre mercado é quem determina a alocação mais eficiente;

d) o livre mercado pressupõe o maior grau possível de concorrência entre os agentes que nele atuam; 
e) valores como o ideal de justiça não devem influenciar a formulação/interpretação/aplicação das normas, por ser desestabilizadora;

f) o escopo do Direito é a busca da eficiência alocativa; e

g) como a eficiência alocativa é o resultado da soma das preferências individuais, é legítimo que ela seja o foco do ordenamento jurídico.

Verifica-se, assim, uma relação entre a máxima efetividade dos direitos fundamentais com o Ótimo de Pareto, uma vez que sempre se deve buscar a realização plena de um direito fundamental sem que outro seja afetado de modo negativo. A situação perfeita seria não prejudicar ninguém, mas como isso às vezes é impossível por ser inerente na sociedade um conflito de interesses, tenta-se prejudicar o mínimo possível a situação de outras pessoas, como se busca na economia também com a eficiência de Kaldor-Hicks (ou Walfare Economics), na qual o saldo é que tem que ser positivo (MARMELSTEIN, 2008).

Considerando o postulado “e”, a referida escola cria diretrizes para a formulação/aplicação/interpretação das normas. Paula A. Forgioni (2005, p. 244/247) destaca como diretrizes:

a) nenhum direito é absoluto, sendo necessário analisar os custos e os benefícios para todas as partes envolvidas na relação, e não apenas para uma delas;

b) o sistema jurídico deve se preocupar em reduzir os custos de transação;

c) deve haver "marcos regulatórios", visando ao aumento da segurança e previsibilidade;

d) a intervenção do estatal deve ser mínima, apenas para neutralizar falhas de mercado;

e) as norma jurídicas devem ser consideradas como incentivo ou não-incentivo à determinada conduta; e

f) a função do Direito é possibilitar a melhor eficiência alocativa.

Segundo David Friedman (2004, p. 40), ela pode servir bastante ao Direito, de modo que formulou nesse sentido as seguintes proposições:

a) a análise econômica do direito pode identificar os efeitos de uma norma jurídica ou decisão;

b) ela permite que uma norma encontre seu lugar no ordenamento jurídico, em prol de uma alocação mais eficiente; e 
c) ela identifica quais normas são melhores para a economia e que devem ser acolhidas.

Todavia, no Brasil não se permite uma aplicação pura de suas teorias, em função de barreiras constitucionais que não permitem que sejam levados em conta apenas postulados econômicos, mas os valores da Análise Econômica do Direito podem ser utilizados para maximizar resultados. O que se espera com este estudo, então, é chamar a atenção para o operador do Direito não ver a análise econômica com maus olhos, havendo uma complementariedade e não substituição ou oposição (FORGIONI, 2005, p. 256).

\title{
3 POR QUE JURISTAS E ECONOMISTAS DEVEM CONVERSAR MAIS?
}

Como se verificou no primeiro tópico deste trabalho, a Análise Econômica do Direito é um assunto interdisciplinar, reunindo Economia e Direito e facilitando a compreensão de ambos. Robert Cooter e Thomas Ulen (2010, p. 33), inclusive, em sua obra "Direito \& Economia”, destacam:

\begin{abstract}
A Economia nos ajuda a perceber o direito de uma maneira nova, que é extremamente útil para os advogados e para qualquer pessoa interessada em questões de políticas públicas. Você provavelmente já está acostumado a conceber as regras da lei como ferramentas para a justiça. Com efeito, muitas pessoas veem o direito apenas em seu papel de provedor de justiça. Este livro ensinará você a ver as leis como incentivos para mudar o comportamento - isto é, como preços implícitos - e como instrumentos para atingir objetivos de políticas públicas (eficiência e distribuição).
\end{abstract}

Embora muitas vezes o foco seja o que a Economia possa trazer para o Direito, ressalta-se que o Direito também tem um papel direto na Economia, quando se trata, por exemplo, de instituições jurídicas como a propriedade e o contrato. “A ausência de propriedade segura e contratos confiáveis costumava paralisar a economia de alguns países da Europa oriental e do terceiro mundo" (COOTER; ULLEN, 2010, p. 33), de modo que os planos de desenvolvimento econômico desses países seja a instituição de regimes jurídicos previsíveis e estáveis. Outro exemplo seriam as diferenças nas leis que influenciam diretamente a atuação de determinado país no mercado de capitais.

Além disso, 
os economistas podem aprender técnicas dos juristas. Os advogados passam boa parte de seu tempo tentando resolver problemas práticos, e as técnicas de análise jurídica foram moldadas por essa dedicação à prática. O resultado de uma ação judicial muitas vezes gira em torno de uma articulação cuidadosa dos fatos (o que é uma aptidão admirável em si mesma) e dos rótulos usados para descrever esses fatos; os estudantes de direito aprendem a ser sensíveis a distinções verbais. Essas distinções verbais, que às vezes parecem sofismas a quem não é jurista, baseiam-se em fatos sutis e importantes que os economistas têm ignorado. Para ilustrar: os economistas muitas vezes exaltam as virtudes das trocas voluntárias, mas a economia não tem uma explicação detalhada do que significa o fato de as trocas serem voluntárias. Como veremos, o direito contratual tem uma teoria complexa e bem articulada da volição. Se os economistas prestarem atenção no que o direito tem a lhes ensinar, verão que seus modelos irão ficar mais próximos da realidade. (COOTER; ULLEN, 2010, p. 33)

E um tema no qual se verifica com intensidade por que juristas e economista devem conversar mais é o contrato. Com base na obra de Ricardo Thielmann (2013, p. 2), a economia não é uma ciência da escolha, mas a ciência do contrato, se analisada com base nos custos de transação. Os contratos são incompletos, em razão da racionalidade limitada, o que geram inúmeros riscos, mas quais devem ser aceitos e como os diminuir?

Destaca-se que a transação não é um fenômeno natural e histórico, sendo um fenômeno econômico que depende de arranjos institucionais que incluem o Estado e outras instituições. A transação não é uma simples troca bilateral de bens, mas transferência de propriedade. Como afirma o autor (2013, p. 2), deve-se compreender “como se dá a transação e qual o comportamento dos indivíduos que transacionam, dado que uma das principais tarefas da organização econômica é coordenar as ações dos indivíduos para buscar reduzir os custos de transação e, assim, promover o equilíbrio econômico desejado”.

Os custos de transação podem ser de dois tipos: 1) ex ante: custos de elaboração e negociação; e 2) ex post: para manutenção de um acordo, podendo ter 4 formas: a) custos incorridos da falta de alinhamento do acordo; b) custos de barganha incorridos para corrigir distorções após o acordo; c) custos de configuração e funcionamento das estruturas de governança para solucionar possíveis disputas; e d) custos de efetivação de uma união segura.

Quando se faz um acordo, ele pode ser extremamente completo ou pode conter muitas lacunas, e os custos de transação seriam determinados pelas incertezas envolvidas na transação (é possível identificar muitos aspectos relevantes que podem afetar a transação?), frequência das operações (são recorrentes?) e grau de especificidade dos ativos (é específico o ativo?). Geram custos de transação também dois aspectos comportamentais: racionalidade limitada 
(incapacidade de analisar tudo referente a uma transação) e a existência do oportunismo (transmissão de informação seletiva, distorcida e promessas autodesacreditadas).

Sobre esses temas, importante também a obra da Professora Paula Forgioni. No que tange à racionalidade limitada, a autora (2009, p. 66/69) diz: “ao contratar, a parte não possui todas as informações existentes sobre a outra, sobre o futuro e sobre a própria contratação; dizse, assim, que sua racionalidade é limitada”. Ao contrário do que prega a economia clássica, as habilidades humanas de cognição são finitas, mas os agentes econômicos buscam agir de forma racional.

Salienta-se que a concepção da racionalidade limitada não nega o pressuposto de que os agentes econômicos são racionais, mas afirma que exercem essa racionalidade dentro das fronteiras impostas pela condição humana e pelo contexto que se inserem. A comunicação é custosa e os entendimentos são sempre deficientes.

O Direito Empresarial, nesse contexto, também entende não ser possível o empresário deter todas as informações e por isso cria mecanismos para lidar com essa incompletude, sendo um exemplo o instituto da excessiva onerosidade, que permite a denúncia do contrato em determinados casos. Uma diferença entre o Direito e a Economia seria quando os economistas consideram algo como um problema e os juristas consideram como oportunidades, como no caso de valorização de uma moeda, que pode ser mais possibilidade de ganhos, envolvendo estratégias.

É um vetor dos contratos empresariais também a incompletude contratual, de modo que Paula Forgioni (2009, p. 70/73) diga que “muitos contratos não contêm - e não podem mesmo conter - a previsão sobre todas as vicissitudes que serão enfrentadas pelas partes”. Já que as partes não possuem todas as informações, é natural que o contrato seja incompleto. Há a impossibilidade de previsão do futuro (podem surgir oscilações de mercado ou inovações tecnológicas, por exemplo), improbabilidade do acontecimento de certos fatos, de modo que não compense cogitar, e há ainda a imprecisão da expressão do acordo, isto é, ainda que trate a questão ela pode ser interpretada de mais de uma forma. E para o ente que realizou investimentos em ativos específicos, aumentando seu grau de dependência, a incompletude representa perigo mais elevado, pois pode incitar comportamento oportunista da outra parte.

Revista Brasileira de Direito Civil em Perspectiva | e-ISSN: 2526-0243 | Salvador | v. 4 | n. 1 | p. 61 - 79 | Jan/Jun. 2018 


\section{A IMPORTÂNCIA DA ANÁLISE ECONÔMICA DO DIREITO E CONEXÕES COM O DIREITO CIVIL}

Sobre o oportunismo, a autora (2009, p. 65/66) diz que "a parte, ao celebrar um contrato, gostaria de vincular o parceiro comercial, mas também de permanecer livre para deixar aquela relação e abraçar outra que eventualmente se apresente mais interessante”. Então, torna-se importante a força obrigatória dos contratos. Além disso, destaca-se que "a empresa tende a utilizar a informação que detém em proveito próprio, e não naquele da contraparte” (FORGIONI, 2009, p. 144/145).

Dessa análise, conclui-se que “o negócio jurídico somente pode ser entendido na complexidade de seu contexto, cuja análise requer visão interdisciplinar” (FORGIONI, 2009, p. 73/74), não sendo possível desgarrar o negócio da realidade em que está inserido. A atividade empresária, por exemplo, depende de uma ação, e ela é conformada pelos fatores políticos, econômicos, sociais e jurídicos.

Fica muito evidente, então, como Economia e Direito devem andar juntos, mas como há ainda uma resistência da Análise Econômica do Direito, propôs-se este trabalho para demonstrar algumas conexões entre o Direito Civil e a referida escola, o que é de extrema importância em prol de uma maior eficiência nas relações.

\section{CONEXÕES ENTRE O DIREITO CIVIL E A ANÁLISE ECONÔMICA DO DIREITO}

Estabelecida a importância da Análise Econômica do Direito e como ela está diretamente relacionada à realidade fática do mundo jurídico, faz-se um recorte metodológico verificando a aplicação da metodologia da ciência econômica junto ao Direito Civil, notadamente quanto aos institutos da propriedade, responsabilidade civil e contratos.

No que tange aos direitos de propriedade, os autores Eduardo Goulart Pimenta e Henrique Avelino R. P. Lana (2010, p. 116) propõem reflexões sobre a necessidade ou não de zelar pelos direitos à propriedade privada em relação aos bens escassos. Seria mais eficiente a propriedade privada com proprietários pré-estabelecidos, ou a propriedade comum? Como se percebe, essa reflexão tangencia diretamente os temas da reforma agrária, desapropriação de imóveis e usucapião, o que ressalta a importância da discussão.

Como explicado pelo Professor César Fiuza (2010, p. 766),

Revista Brasileira de Direito Civil em Perspectiva | e-ISSN: 2526-0243 | Salvador | v. 4 | n. 1 | p. 61 - 79 | Jan/Jun. 2018 
no grande universo do Direito das Coisas, propriedade pode ser definida como a situação jurídica consistente em uma relação dinâmica e complexa entre uma pessoa, o dono, e a coletividade, em virtude da qual são assegurados àquele os direitos exclusivos de usar, fruir, dispor e reivindicar um bem, respeitados os direitos da coletividade. Essa definição se amolda melhor aos ditames da modernidade e do paradigma do Estado Democrático de Direito.

Mas quais seriam os fundamentos para a existência da propriedade? O Professor César Fiuza (2010, p. 772/773) apresenta algumas teorias para responder essa pergunta, sendo pertinente a teoria da natureza humana, pela qual a propriedade tem como fundamento a própria natureza humana, ou seja, é algo natural o ser humano querer exercer poder sobre as coisas. Até nos países socialistas há o reconhecimento da propriedade privada, porém nesses casos não será para todos os bens, envolvendo apenas os de uso particular. Segundo o autor (2010, p. 772/773),

se tem por origem a natureza do homem, é perfeitamente legítima a propriedade. [...]
Mesmo tratando-se de sociedade em que a propriedade é coletiva, há um sentimento
forte de exclusividade quanto a terceiros estranhos. Isso ocorre tanto em comunidades
humanas quanto em agrupamentos animais. Assim, os homens defendem seu
território, bem como fazem os leões.

O homem, como ser racional, ainda que de forma limitada, pode prever seu futuro e, “para subsistir economicamente hoje e no tempo futuro, o homem precisa tornar-se proprietário de bens naturais, de consumo, fungíveis e de produção” (PIMENTA; LANA, 2010, p. 117).

A propriedade é o direito real por excelência, em torno do qual gravita o direito das coisas, sendo de tamanha importância, tanto é que está expresso no caput do art. $5^{\circ}$ da Constituição de 1988: “Todos são iguais perante a lei, sem distinção de qualquer natureza, garantindo-se aos brasileiros e aos estrangeiros residentes no País a inviolabilidade do direito à vida, à liberdade, à igualdade, à segurança e à propriedade (...)”.

A propriedade pode ser colocada como direito subjetivo, fundamental e garantia institucional, assegurando bens jurídicos indispensáveis à preservação de certos valores tidos como essenciais (FARIAS; ROSENVALD, 2012, p. 280). Para ser, é preciso ter, e quanto a isso importantes os ensinamentos de Hannah Arendt (2008, p. 81):

Importante feição não privativa da privatividade é que as quatro paredes da propriedade particular de uma pessoa oferecem o único refúgio seguro contra o mundo público comum - não só contra tudo que nele 
ocorre mas também contra a sua própria publicidade, contra o fato de ser visto e ouvido. Uma existência vivida inteiramente em público, na presença de outros, torna-se, como diríamos, superficial. Retém a sua visibilidade, mas perde a qualidade resultante de vir à tona a partir de um terreno mais sombrio, terreno este que deve permanecer oculto a fim de não perder sua profundidade num sentido muito real e não subjetivo. O único modo eficaz de garantir a sombra do que deve ser escondido contra a luz da publicidade é a propriedade privada - um lugar só nosso, no qual podemos nos esconder.

Como explica Cristiano Chaves de Farias e Nelson Rosenvald (2012, p. 280), “a proteção da liberdade, privacidade, integridade psíquica, por si, já justifica a permanência da propriedade como instituição, direitos subjetivos”. Embora a liberdade não garanta, por si só, liberdade e direitos civis, ela é um dispositivo eficiente para assegurá-los. Com a propriedade, há a criação de um ambiente no qual nem o Estado nem a sociedade podem cometer transgressões.

Como se verifica, o direito da propriedade existe em prol da própria dignidade da pessoa humana, pois o homem "tem necessidade de apropriar-se exclusivamente de certos bens para orientar sua atividade segundo suas aspirações e gostos, podendo trabalhar, sem coação, no desenvolvimento de sua personalidade” (PIMENTA; LANA, 2010, p. 118). Todavia, o exercício desse direito, obviamente, deve se dar de acordo com a conveniência social e, havendo eventual conflito, o interesse social pode prevalecer sobre o individualizado.

Mas como justificar a existência da propriedade privada com base na Análise Econômica da Direito? Inicialmente, importante falar sobre a eficiência maximizada, uma vez que quando o bem é comum e pode ser usufruído por vários indivíduos há um “efeito negativo recíproco, haja vista que as atuações de cada agente geram custos e exaurimento do bem escasso” (PIMENTA; LANA, 2010, p. 119).

Como extraído da obra de Harold Demsetz (1967), há uma estreita relação entre direitos de propriedade e externalidades. Como explica Eduardo Goulart Pimenta (2017, p. 36),

externalidade é, em síntese, a consequência que o ato de uma pessoa física ou jurídica provoca sobre os direitos de terceiros, naqueles casos em que não o agente, mas os terceiros afetados pelo ato em questão, arcam com os custos advindos desta conduta ou auferem os ganhos dela decorrentes. Quando o ato praticado provoca um efeito negativo sobre os direitos de terceiros e estes efeitos negativos são custeados por eles, 
fala-se em externalidade negativa. Quando, ao contrário, o ato praticado provoca um efeito positivo sobre os direitos de terceiros e estes ganhos não são custeados por eles, verifica-se uma externalidade positiva.

Nesse mesmo sentido, corroborando o exposto, Gregory Mankiw (2005, p. 204) diz:

uma externalidade surge quando uma pessoa se dedica a uma ação que provoca impacto no bem-estar de um terceiro que não participa dessa ação, sem pagar nem receber nenhuma compensação por esse impacto. Se o impacto sobre o terceiro é adverso, é chamado externalidade negativa; se é benéfico, é chamado de externalidade positiva.

Como exemplo, cita-se a exploração de um pasto por criadores de animais. Se não houver limites impostos, todos irão tentar tirar o máximo de proveito possível daquele terreno, o que levaria ao fim do bem que é escasso, com um prejuízo para todos. A questão, portanto,

não é tanto se eficiência pode ser igualada à justiça, mas sim como a construção da justiça pode se beneficiar da discussão de prós e contras, custos e benefícios. Noções de justiça que não levem em conta as prováveis consequências de suas articulações práticas são, em termos práticos, incompletas. Num certo sentido, o que a Escola de Direito e Economia de New Haven buscou é congregar a ética consequencialista da Economia com a deontologia da discussão do justo. O resultado é, em primeiro lugar, a abertura de uma nova janela do pensar, que integra novas metodologias (inclusive levantamentos empíricos e estatísticos) ao estudo das instituições jurídico-políticas, de forma que o Direito possa responder de modo mais eficaz às necessidades da sociedade. E, em segundo lugar, o enriquecimento da gramática do discurso jurídico tradicional, com uma nova terminologia que auxilia o formulador, o aplicador, e o formulador da lei na tarefa de usar o Direito como instrumento do bem comum. (SALAMA, 2008, p. 24)

Quando há uma propriedade que não é comum, há um incentivo para se utilizar de forma mais eficiente, pois os custos em regra serão internalizados por aquele que explora. Se ele explorar de forma ineficiente, quem terá mais custos será ele mesmo. Citando Harold Demsetz (1967, p. 2),

La 'internalización’ de tales efectos está ligada a un proceso - usualmente un cambio en los derechos de propiedad- que permite a dichos efectos gravitar sobre todas las personas interactuantes. Una función primaria de los derechos de propiedad es la de promover incentivos para alcanzar una mayor internalización de las externalidades. Cada costo y beneficio asociado con interdependencias sociales es una externalidad potencial. 
Então, quando se sabe quem é o proprietário, diminuem-se os custos de transação, que “consistem naquilo que se precisa pagar ou de que se deve abrir mão para constituir, manter, proteger ou transferir os direitos e deveres decorrentes de uma relação contratual” (PIMENTA, 2012, p. 4922). Pode-se dizer ainda que:

\begin{abstract}
Custos de transação - ou custos de contratação - representam aquilo que dispenderam ou deixaram de ganhar as partes de um contrato com o objetivo de constituí-lo ou executá-lo. São os custos que os contratantes enfrentam para elaborar, manter e fazer cumprir o contrato. A importância dos custos de transação se tornou evidente a partir do seminal trabalho de Ronald Coase e hoje é fundamental para a análise econômica do Direito pois, conforme se depreende do denominado Teorema de Coase, quanto maiores forem os custos da transação, menores serão as chances das partes chegarem a contratar. (PIMENTA, 2017, p. 43)
\end{abstract}

Além disso, é muito menos custoso um só decidir do que buscar o consenso de vários que se entendem como proprietários. De toda forma, percebe-se que se estabelecerem previamente os proprietários dos bens, há utilização mais eficiente e racional, com uma duração maior do recurso, sendo essa a essência dos direitos de propriedade para a Análise Econômica do Direito (PIMENTA; LANA, 2010, p. 124).

Esse raciocínio também pode ser aplicado aos direitos de propriedade autoral e das patentes, uma vez que

caso o ordenamento jurídico não preveja proteção ou benefícios ao proprietário e responsável por determinada autoria científica de um objeto ou ideia específica, não haverá incentivos para que novas criações sejam feitas. Não haverá incentivo ao progresso intelectual. Todos os não-criadores se sentirão proprietários de determinada ideia ou objeto e usufruirão livremente e comumente da mesma. (PIMENTA; LANA, 2010, p. 126)

Deve-se, assim, ser aplicada a Análise Econômica do Direito aos direitos de propriedade, em prol de uma maior eficiência e racionalidade.

Quanto à relação entre a Análise Econômica do Direito e a Responsabilidade Civil, também é possível trazer algumas reflexões. A responsabilidade civil, como bem explicado por Flávio Tartuce (2016, p.483), surge em face do descumprimento de determinada obrigação, pela desobediência a uma regra contratual, ou por deixar de observar um preceito normativo 
que regule a vida. Nota-se, então, que a responsabilidade civil pode ser negocial ou contratual e extracontratual (aquiliana).

Independente disso, os custos decorrentes da responsabilidade civil podem decorrer de acidentes ou de sua prevenção, de modo que na prevenção há um incentivo para que as pessoas não atuem em atividades que podem ocasionar danos, e, caso haja o dano, fala-se no caráter ressarcitório, com a devida reparação de eventuais perdas e danos sofridos.

Embora em teoria deva se buscar uma prevenção total, ela é economicamente inviável e pouco eficiente, considerando que seria algo impossível na prática e de elevado custo. Nesse contexto, fala-se no dano eficiente, que o Professor César Fiúza (2010, p. 740/741) bem explica:

\begin{abstract}
Fala-se, outrossim, em dano eficiente e dano ineficiente. Ocorre dano eficiente, quando for mais compensador para o agente pagar eventuais indenizações do que prevenir o dano. Se uma montadora verificar que uma série de automóveis foi produzida com defeito que pode causar danos aos consumidores, e se esta mesma empresa, após alguns cálculos, concluir ser preferível pagar eventuais indenizações pelos danos ocorridos, do que proceder a um recall para consertar o defeito de todos os carros vendidos que lhe forem apresentados, estaremos diante de dano eficiente. $\mathrm{O}$ dano ineficiente, por seu turno, é o dano eficiente tornado ineficiente pela ação dos órgãos administrativos do Estado e/ou do Judiciário. Na medida em que o juiz condenar a montadora a uma altíssima indenização, ao atuar em ação indenizatória proposta por um dono de automóvel, vitimado pelo dano causado pelo defeito de produção, estará transformando o dano eficiente em dano ineficiente. As eventuais indenizações que a montadora terá que pagar serão tão altas, que será preferível o recall, por ser mais barato. A questão relativa ao dano ineficiente é equacionar duas questões. Por um lado, o valor da condenação há de ser alto, para que o dano seja de fato ineficiente para seu causador. Por outro lado, deve-se ter em conta que indenização não deve ser fonte de enriquecimento, mas de reparação de danos. $\mathrm{O}$ problema é de difícil solução, exigindo do juiz um enorme exercício de bom-senso e, às vezes, de coragem. O legislador poderia pôr fim ao dilema, editando norma, segundo a qual parte do valor da condenação iria para a vítima, a título de reparação pelos danos sofridos, enquanto a outra parte reverteria aos cofres públicos, sendo afetada à utilização em programas sociais.
\end{abstract}

É importante refletir sobre os milhares de processos judiciais que se instauram diariamente com pedidos de indenização por danos morais, envolvendo negativações indevidas, extravio de bagagens, atrasos em prestação de serviços, dentre inúmeros outros casos. Os fornecedores e prestadores de serviços conseguem prever o dano eventualmente a ser ocorrido em suas relações e o custo é muito mais importante para o empresário que o caráter pedagógico de eventual indenização a ser aplicada. Como há a possibilidade de saber aproximadamente os valores de eventual condenação, considerando um tabelamento perceptível no dia a dia da 


\title{
A IMPORTÂNCIA DA ANÁLISE ECONÔMICA DO DIREITO E CONEXÕES COM O DIREITO CIVIL
}

atividade forense, há um incentivo para que não haja prevenção do dano. A Análise Econômica do Direito pode ter um papel fundamental, assim, para buscar um equilíbrio mais eficiente entre prevenção e dano, propondo incentivos em prol da prevenção (PIMENTA; LANA, 2010, p. 129).

Por fim, faz-se uma análise da relação da Análise Econômica do Direito com os contratos civis. Como afirma Roppo (2001, p. 56), “na economia moderna, é o contrato, acima de tudo, que cria a riqueza” e, sem a pretensão de esgotar o conceito de contrato, pode-se dizer que contrato é

[...] é a convenção, pacto ou acordo para execução de algo sob determinadas condições entre as partes contratantes. A vida moderna, com o avanço da tecnologia nos obriga a ampliar as relações entre as pessoas, praticando atos jurídicos através de convenções recíprocas, geradoras do contrato. Contrato, portanto, é ato jurídico em que duas ou mais pessoas se obrigam ou convencionam, por consentimento recíproco, a dar, fazer ou não fazer alguma coisa, verificando, assim, a constituição, modificação ou extinção do vínculo patrimonial. (JUNQUEIRA, 2011, p. 27)

Como se verifica, o contrato traz limitações às partes contratantes, prevendo direitos e deveres. Segundo a Análise Econômica do Direito, as partes buscam o contrato, mesmo com as limitações que ele traz, uma vez que o resultado para a coletividade, em geral, é maior que quando agem com base nas intenções individuais e privadas exclusivamente (PIMENTA; LANA, 2010, p. 130). Como afirmam Eduardo Goulart Pimenta e Henrique Avelino R. P. Lana (2010, p. 130),

\begin{abstract}
a Análise Econômica do Direito aduz que os contratos são instrumentos adequados a compor os riscos da própria atividade econômica, diminuindo eventual perda e prejuízo do agente contratante, possibilitando um contexto mais eficiente. O cumprimento dos contratos em geral, é premissa fundamental para o desenvolvimento de um país e, justamente por isso, é uma das searas nas quais a Análise Econômica do Direito merece ser aplicada.
\end{abstract}

Sendo assim, a proteção legal e judicial será fundamental para que os contratos sejam cumpridos, gerando maior eficiência e dinamicidade econômica. Como um círculo virtuoso, “a proteção da legítima expectativa aumentará o grau de segurança e de previsibilidade do mercado; o resultado será a diminuição dos custos de transação e, portanto, a catalisação do 
tráfico” (FORGIONI, 2009, p. 99). Porém, a confiança não é adquirida de imediato, de forma que a medida que mais negócios sejam feitos diminuam os custos de transação nesse aspecto.

Para encerrar este trabalho, salienta-se que a Análise Econômica do Direito não fica restrita ao Direito Privado, havendo também inúmeras conexões com todo o Direito, citando, por exemplo, a relação com o processo e os crimes/penas.

\section{CONCLUSÃO}

Como se verificou ao longo do trabalho, Economia e Direito devem andar juntos, pois um influencia diretamente no outro, e uma forma de pensá-los juntos é por meio da Análise Econômica do Direito, escola que tem como finalidade a implementação dos postulados econômicos na aplicação e interpretação do Direito, para que se tenha uma maior eficiência nas relações.

Nesta pesquisa, diante da impossibilidade de se mostrar as conexões entre Economia e todos os ramos do Direito, fez-se um recorte metodológico no Direito Civil, que embora seja Direito Privado, possui ainda uma certa resistência quanto à aplicação de postulados econômicos, talvez por conta de uma preferência de vários autores por um viés mais existencialista que patrimonialista.

No caso do Direito Civil, escolheu-se a análise perante os institutos da propriedade, responsabilidade civil e contratos. No caso da propriedade, verificou-se por uma análise econômica que é mais eficiente a propriedade privada com proprietários pré-estabelecidos do que a propriedade comum. É interessante observar que o direito da propriedade existe em prol da própria dignidade da pessoa humana, pois é da natureza humana a necessidade de apropriarse exclusivamente de certos bens para o desenvolvimento da personalidade.

A justificativa da existência da propriedade privada com base na Análise Econômica da Direito se dá com base na eficiência maximizada, uma vez que quando o bem é comum e pode ser usufruído por vários indivíduos há um efeito negativo recíproco. Se houver uma o estabelecimento prévio dos proprietários dos bens, há utilização mais eficiente e racional, com uma duração maior do recurso, sendo essa a essência dos direitos de propriedade para a Análise

Revista Brasileira de Direito Civil em Perspectiva | e-ISSN: 2526-0243 | Salvador | v. 4 | n. 1 | p. 61 - 79 | Jan/Jun. 2018 


\section{A IMPORTÂNCIA DA ANÁLISE ECONÔMICA DO DIREITO E CONEXÕES COM O DIREITO CIVIL}

Econômica do Direito. Esse raciocínio, inclusive, também pode ser aplicado aos direitos de propriedade autoral e das patentes.

Quanto à responsabilidade civil, notou-se que a Análise Econômica do Direito pode ter um papel fundamental para buscar um equilíbrio mais eficiente entre prevenção e dano, propondo incentivos em prol da prevenção. Em muitas relações, compensa para fornecedores, por exemplo, causar um dano, pois o custo que teriam para prevenir é superior ao do dano em si, e uma análise econômica permite que se mapeie melhor isso e atinja uma maior eficiência para todos.

Por fim, analisaram-se os contratos sob o foco da Análise Econômica do Direito. Embora o contrato imponha limitações às partes contratantes, verifica-se que essas limitações trazem um resultado positivo para a coletividade. O cumprimento dos contratos torna-se premissa fundamental para o desenvolvimento de um país, e a proteção legal e judicial será fundamental para que os contratos sejam cumpridos, gerando maior eficiência e dinamicidade econômica.

O que se tentou com este estudo é demonstrar ao leitor como uma análise econômica pode trazer mais eficiência ao Direito. Mas é claro que uma análise puramente econômica pode levar a absurdos que contrariam totalmente noções de justiça, então o que se propôs é a sua complementariedade, e não sua substituição ou oposição.

\section{REFERÊNCIAS}

ARENDT, Hannah. A condição humana. 10ª ed. Rio de Janeiro: Forense Universitária, 2008.

BRASIL. Constituição da República Federativa do Brasil de 1988. Disponível em: $<$ http://www.planalto.gov.br/ccivil_03/constituicao/constituicao.htm>. Acesso em: 23/01/2018.

COOTER, Robert; ULLEN, Thomas. Direito \& Economia. Porto Alegre: Bookman, 2010.

DEMSETZ, Harold. Hacia uma teoría de los derechos de propriedad. Traduzido de American Economic Review, maio de 1967. Disponível em: $<$ http://www.eumed.net/cursecon/textos/Demsetz_teoria-derechos-propiedad.pdf $>$. Acesso em: 23/01/2018. 
FARIAS, Cristiano Chaves de; ROSENVALD, Nelson. Curso de Direito Civil: Reais. $8^{\mathrm{a}}$ ed. Salvador: JusPodivm, 2012.

FIUZA, César. Direito Civil: curso completo. 14ª ed. Belo Horizonte: Del Rey, 2010.

FORGIONI, Paula A. Análise econômica do direito (AED): Paranóia ou mistificação? In: Revista de direito mercantil, industrial, econômico e financeiro. São Paulo: Malheiros, Ano XLIV, julho-setembro/2005.

FORGIONI, Paula. Teoria geral dos contratos empresariais. São Paulo: Revista dos Tribunais, 2009.

FRIEDMAN, David D. L'ordine del diritto: Perché l'analisi economica può servire al diritto. Bolonha: Il Mulino, 2004.

JUNQUEIRA, Gabriel José Pereira. Contratos em Geral no Novo Código Civil: comentado artigo por artigo - teoria - prática. São Paulo: Imperium Editora e Distribuidora, 2006. Revista do CAAP, Belo Horizonte, n. 2, V.XVII, 2011, p. 241-259.

LANA, Henrique Avelino Rodrigues de Paula; PATROCÍNIO, Daniel Moreira do. O Dano Eficiente e Análise Econômica do Direito: uma Visão Consumerista. Disponível em: $<$ http://www.editoramagister.com/doutrina_24551030_O_DANO_EFICIENTE_E_ANALISE _ECONOMICA_DO_DIREITO_UMA_VISAO_CONSUMERISTA.aspx>. Acesso em: 23/01/2018.

MANKIW, Gregory. Introdução à Economia. $3^{\mathrm{a}}$ ed. São Paulo: Thomson. 2005.

MARMELSTEIN, George. Análise Econômica dos Direitos Fundamentais. Disponível em: $<$ http://direitosfundamentais.net/2007/12/14/analise-economica-dos-direitos-fundamentais/>. Acesso em 01/07/2015.

MONTEIRO, Renato Leite. Análise Econômica do Direito: uma visão didática. Disponível em: $<$ http://www.publicadireito.com.br/conpedi/manaus/arquivos/Anais/sao_paulo/2425.pdf>.

Acesso em 18/07/2015.

PIMENTA, Eduardo Goulart. Direito, Economia e relações patrimoniais privada. Brasília a. $43 \quad$ n. 170 abr.jun. 2006. Disponível em: <http://www2.senado.leg.br/bdsf/bitstream/handle/id/92839/Pimenta\%20Eduardo.pdf?sequen ce $=1>$. Acesso em: 24/01/2018.

PIMENTA, Eduardo Goulart. Direito societário. Porto Alegre: Editora Fi, 2017.

PIMENTA, Eduardo Goulart; LANA, Henrique Avelino R. P. Análise Econômica do Direito e sua relação com o Direito Civil brasileiro. Rev. Fac. Direito UFMG, Belo Horizonte, n. 57, p. 85-138, jul./dez. 2010.

Revista Brasileira de Direito Civil em Perspectiva | e-ISSN: 2526-0243 | Salvador | v. 4 | n. 1 | p. 61 - 79 | Jan/Jun. 2018 


\section{A IMPORTÂNCIA DA ANÁLISE ECONÔMICA DO DIREITO E CONEXõES COM O \\ DIREITO CIVIL}

PIMENTA, Eduardo Goulart. Teoria da Empresa em Direito e Economia. RIDB, Ano 1 (2012), $n^{\circ}$ 8. Disponível em: <http://www.idb-fdul.com/>. Acesso em: 25/09/2017.

ROPPO, Vincenzo. Il contrato. Milano: Giuffrè, 2001.

ROSSETTI, José Paschoal. Introdução à economia. 20ª ed. São Paulo: Atlas, 2003.

SALAMA, Bruno Meyerhof. O que é pesquisa em Direito e Economia?. Cadernos Direito GV, v. 5, $24, \quad 2008.2$ Disponível $<$ http://bibliotecadigital.fgv.br/dspace/bitstream/handle/10438/2811/caderno\%2520direito\%2 52022.pdf?sequence=1\&isAllowed=y> . Acesso em: 23/01/2018.

SOUZA, Wallace Fabrício Paiva. As relações empresariais contemporâneas e a efetivação dos direitos fundamentais do idoso sob o foco da Análise Econômica do Direito. In: STRAPAZZON, Carlos Luiz; BELLINETTI, Luiz Fernando; COUTINHO, Sérgio Mendes Botrel. Eficácia de Direitos Fundamentais nas Relações do Trabalho, Sociais e Empresariais. Florianópolis: Conpedi, 2015.

TARTUCE, Flávio. Manual de direito civil: volume único. Rio de Janeiro: Forense; São Paulo: Método, 2016

THIELMANN, Ricardo. A Teoria dos Custos de Transação e as Estruturas de Governança: uma Análise do Caso do Setor de Suinocultura no Vale do Rio Piranga - Mg. 2013. Disponível em: <https://www.aedb.br/seget/arquivos/artigos13/991852.pdf>. Acesso em: 25/09/2017. 